Proceedings

\title{
Carbon Screen-Printed Electrode Coated with Poly (Toluidine blue) as an Electrochemical Sensor for the Detection of Tyramine ${ }^{+}$
}

\author{
Lakshmi Devi * and Martin Brandl \\ Center for Water and Environmental Sensors, Donau-Universität Krems, 3500 Krems, Austria; \\ * Correspondence: lakshmi.chakkarapani@donau-uni.ac.at; Tel.: +43-2732-893-2791 \\ + Presented at the 7th International Electronic Conference on Sensors and Applications, 15-30 November \\ 2020; Available online: https://ecsa-7.sciforum.net/.
}

Published: 15 November 2020

\begin{abstract}
In the present work the surface modification of a carbon screen-printed electrode by electrochemical polymerization of Toluidine blue (TB) for determination of tyramine is described. The electrochemical polymerization of the electrode with TB was done by cyclic voltammetry at a scan rate of $50 \mathrm{mV} / \mathrm{s}$ and a potential sweep between $-0.7 \mathrm{~V}$ to $1.0 \mathrm{~V}$ in presence of $0.5 \mathrm{mM}$ TB in an electrolyte solution. At each cycle, the polymer film started to deposited on the carbon screen-printed electrode which was repeated 20 times. For parameter optimization the electrochemical behavior of the modified electrode was analyzed by amperometric methods such as cyclic voltammetry (CV) and differential pulse voltammetry (DPV). A phosphate buffer solution (PBS) was used as an electrolyte for all the amperometric experiments. The electrochemically modified poly-TB coated carbon screen printed electrode showed an oxidation peak potential of tyramine at $0.67 \mathrm{~V}$. The unmodified carbon screen printed electrode showed the tyramine oxidation peak potential at $0.9 \mathrm{~V}$. Based on the voltammetric results, it was found that the poly-TB modified carbon screen printed electrode showed higher sensitivity $\left(1.78 \mu \mathrm{A} \mathrm{nM}^{-1} \mathrm{~cm}^{-2}\right)$ than a bare carbon screen printed electrode towards tyramine detection. Tyramine in $0.1 \mathrm{M}$ PBS (pH 7.4) was analyzed by cyclic voltammetry from the potential of -0.7 to $1.0 \mathrm{~V}$ at a scan rate of $50 \mathrm{mV} / \mathrm{s}$. The Poly-TB modified carbon screen printed electrode exhibited a linear response between catalytic peak current and tyramine concentration from $0.02 \mu \mathrm{M}$ to $270.5 \mu \mathrm{M}$ with a lower detection limit of 0.007 $\mu \mathrm{M}(\mathrm{S} / \mathrm{N}=3)$.
\end{abstract}

Keywords: tyramine; poly (Toluidine blue); sensor; polymerization; oxidation potential

\section{Introduction}

Tyramine (1-hydroxy-4-ethylaminobenzene) is a bioamine which are organic nitrogenous compound that may naturally formed in food by bacterial decarboxylation. Tyramine is relatively present in the byproduct of microbial activity, fermented foods, dairy products, beverages, fish and meat etc [1-4]. High concentration of tyramine contaminated foods consumption may cause negative impact on the human health such as, diarrhea, hypotension, migraine, cardiac failure and low blood pressure etc [5-8]. Tyramine belongs to the group of biogenic amines, including histamine, putrescine and cadaverine. Considering the undesirable physiological effect of tyramine, it is important to develop highly sensitive, selective and low cast methods for tyramine determination in food and beverages. The European food safety authority encourages researchers and provide finding for toxic bioamine analysis from fermented foods $[9,10]$. Currently numerous methods are available for tyramine analysis such as high-performance liquid chromatography [11], mass spectrometry analysis [12], capillary electrophoresis [13] and quantitative PCR [14]. Although Eng. Proc. 2020, 1, Firstpage-Lastpage; doi: FOR PEER REVIEW www.mdpi.com/journal/engproc 
these methods provide lower detection limits and selectivity, they are highly required qualified personnel, more time consumption techniques, difficult pretreatment steps before the experiments, and expensive instrumentation. Thus, alternative tyramine detections are highly desirable. Compared with the traditional analytical methods, electrochemical sensors development for bioamine detection have gained increasing attention due to their selectivity, sensitivity, low cast, user friendly instruments handling, on spot sample analysis and short analysis time [15]. Recently various electro active materials are used for electrochemical sensors development such as conducting polymers, nano materials, nano particles, nanotubes, metal complexes and graphene etc. [16-18]. Among all, conducting polymers modified electrochemical sensor become a hot topic and open a new domain in the area of analytical science.

The present work focuses design and development of conducting polymer coated electrochemical screen-printed sensor for detection of tyramine. Poly (Toluidine blue) is a well-known conducting polymer which is act as an electron transfer mediator over the electrode surface. The electrochemical performance of the developed poly (Toluidine blue) modified screen printed electrode was used for tyramine detection and investigated by voltammetric techniques.

\section{Materials and Methods}

\subsection{Reagents}

Screen printed carbon electrode was purchased from Metrohm Drop Sens (Spain). Tyramine, Phosphate buffer saline (PBS) and Toluidine blue were purchased from Sigma Aldrich (St. Louis, MO, USA). All other reagents and solvent were commercially available and used received unless otherwise specified.

\subsection{Equipment}

Cyclic voltammetry and differential pulse voltammetry were performed by Gamry instruments reference 600+ (potentiostat/Galvanostat ZR) Echem Analyst. The carbon screen-printed electrode (DRP-110) contains single electrochemical cell, each cell contains the carbon paste (CP) as a working electrode (WE), a silver/silver chloride as reference electrode (RE) and a carbon paste as a counter electrode $(\mathrm{CE})$. Electrical connections are made by silver and strips general dimensions: $3.4 \times 1.0 \times$ $0.05 \mathrm{~cm}$. $\mathrm{pH}$ of the electrolyte solutions were measured by $\mathrm{pH}$ meter (VWR).

\subsection{Poly (Toluidine blue) Coated Screen Printed Electrode Preparation}

The screen printed carbon electrode was fixed with the Greamy 600+ electrochemical instrument, silver leads provide the electrical connection between sensor and the potentiostat, thereby avoiding use of cables and make the device user friendly. Toluidine blue $(5 \mathrm{mM})$ was prepared with PBS (0.1 M. pH 7.4). Toluidine blue contain electrolyte solution (100 $\mu \mathrm{L})$ was drop casted on the top of the three electrode system. Cyclic voltammetry was stared to run 20 cycles from $-0.7 \mathrm{~V}$ to $1.0 \mathrm{~V}$ at a scan rate of $50 \mathrm{mV} / \mathrm{s}$. Polymerization slowly increases from 1st cycle to 20th cycle. After the polymerization, the Poly-TB modified screen printed carbon electrode was removed from the electrical connection and washed with double distilled water.

\section{Results and Discussion}

\subsection{Electrochemical Characterization of Poly (Toluidine blue) Screen Printed Carbon Electrode}

Electrochemical coating and sensor development are clearly demonstrated in Scheme 1. Three printed electrode chips were coated with poly (Toluidine blue) polymer film and used for tyramine analysis. To assess the electrochemical performance, the Poly-TB modified screen printed carbon electrode was fabricated and compared with an unmodified screen-printed electrode by cyclic voltammetry in presence of tyramine $(82 \mu \mathrm{M})$ and PBS $(0.1 \mathrm{M}, \mathrm{pH} 7.4)$ at the scan rate of $50 \mathrm{mV} / \mathrm{s}$. Figure 1 shows the cyclic voltammetry results of a bare and a modified electrode. Based on the 
results the Poly-TB modified screen printed carbon electrode showed the tyramine oxidation peak at $0.67 \mathrm{~V}$ and the bare screen printed carbon electrode showed the tyramine oxidation peak at $0.9 \mathrm{~V}$ with significant lower current response. This current variation and potential shift represents that the Poly-TB modified screen-printed carbon electrode has a higher conductivity, catalytic activity, larger active surface area and sensitivity. Furthermore, the modified electrode showed the oxidation peak at $0.19 \mathrm{~V}$ and the reduction peak at $-0.06 \mathrm{~V}$ which represents the poly (Toluidine blue) polymerization $[19,20]$.

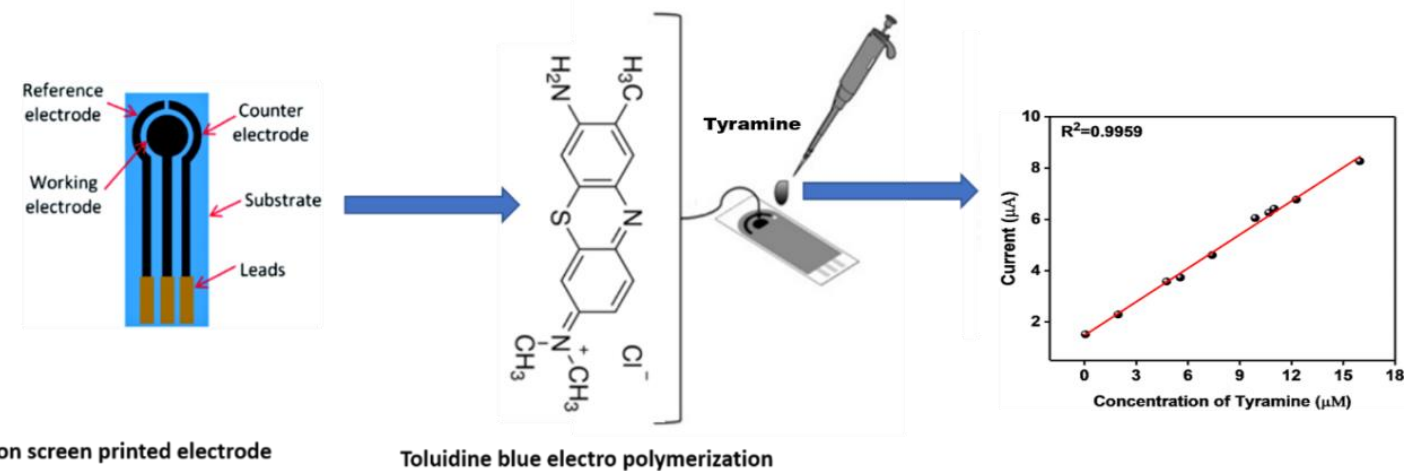

Scheme 1. Electrochemical analysis of tyramine using a poly-TB-carbon screen printed electrode.

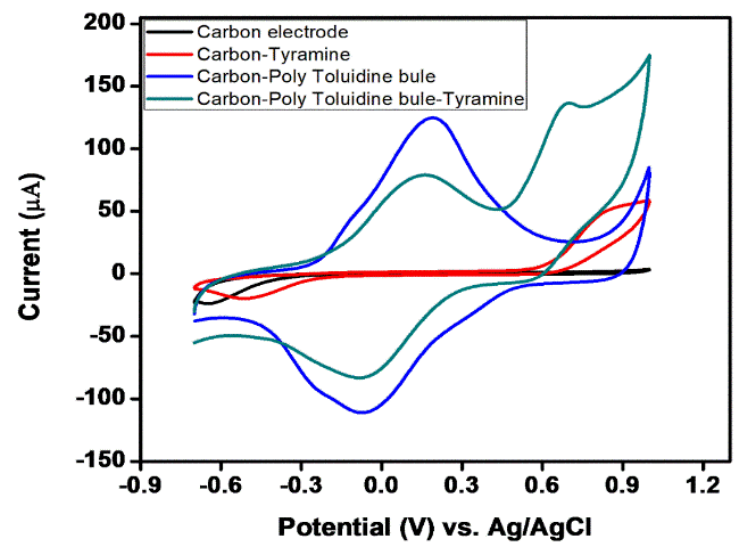

Figure 1. CVs obtained at (black) carbon screen-printed electrode, (red) containing tyramine, (blue) PTB-carbon screen printed modified, (green) containing tyramine $82 \mu \mathrm{M}$ in $0.1 \mathrm{M}$ PBS pH 7.4 and scan a rate of $50 \mathrm{mV} / \mathrm{s}$.

\subsection{Differential Pulse Voltammetry Studies}

The electrochemical behavior of tyramine was analyzed by a Poly-TB modified screen-printed carbon electrode. Figure $2 \mathrm{a}$ showed the continuous successive additions of tyramine from $0.02 \mu \mathrm{M}$ to $16 \mu \mathrm{M}$ with PBS $(0.1 \mathrm{M}, \mathrm{pH} 7.4 \mathrm{~V})$. The oxidation peak appeared at $0.67 \mathrm{~V}$ and the peak current was slowly increased based on the tyramine concentration. Figure $2 \mathrm{~b}$ represents the analytical calibration plot of various concentrations of tyramine vs. the catalytic oxidation current. The anodic current $\left(\mathrm{I}_{\mathrm{pa}}\right)$ was linearly increasing with elevation of the tyramine concentration and the correlation coefficient $\left(R^{2}\right)$ was found to 0.9959 . The lower detection limit (LOD) was calculated as $0.007 \mu \mathrm{M}$ according to the equation $\mathrm{S} / \mathrm{N}=3$, and the sensitivity was $1.78 \mu \mathrm{A} \mathrm{nM}-1 \mathrm{~cm}^{-2}$. It can be seen that the Poly-TB modified screen-printed carbon electrode is the most sensitive sensor for tyramine detection which is offered satisfactory linear range and lower detection limits. 


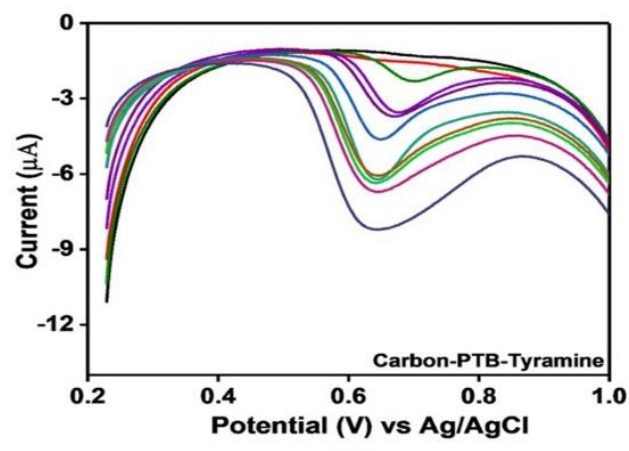

(a)

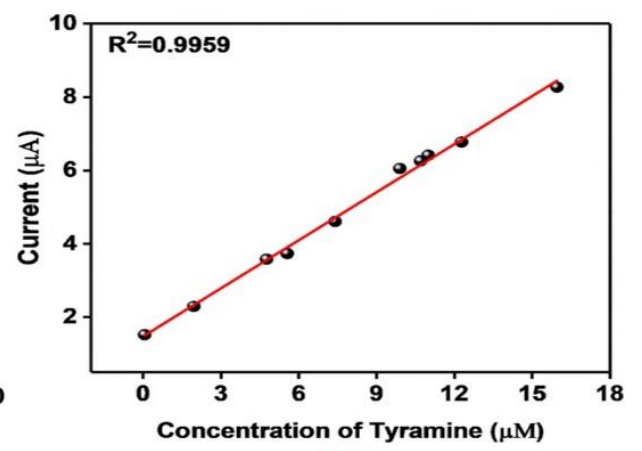

(b)

Figure 2. (a) DPV response of PTB-Carbon screen printed electrode in presence of tyramine $(0.02$ to $16 \mu \mathrm{M}$ ) in $0.1 \mathrm{M}$ PBS of $\mathrm{pH} 7.4$ at a scan rate of $50 \mathrm{mV} / \mathrm{s}$. (b) Calibration plot of the current response vs. the concentration of tyramine.

\subsection{Long-Term Stability Studies}

In order to know the lifetime of the Poly-TB modified screen-printed carbon sensor, measurements were done in a 5 days interval, in presence of tyramine $(82 \mu \mathrm{M})$ with PBS $(0.1 \mathrm{M}, \mathrm{pH}$ 7.4 ) at the scan rate of $50 \mathrm{mV} / \mathrm{s}$. The analysis was done almost 60 days and the results were recorded. Based on the results, the developed sensor retained $97 \%$ response at the end of 60 days (Figure 3). The operating long-term stability of Poly-TB modified screen-printed carbon modified electrode was investigated by injecting $82 \mu \mathrm{M}$ of tyramine in the electrochemical cell every 30 min over extended period of $7 \mathrm{~h}$ (inserts). The recorded results do not show any significant changes during the time duration. These results confirmed that the Poly-TB modified screen-printed carbon sensor has both excellent storage capacity and operational stability as an amperometric tyramine sensor.

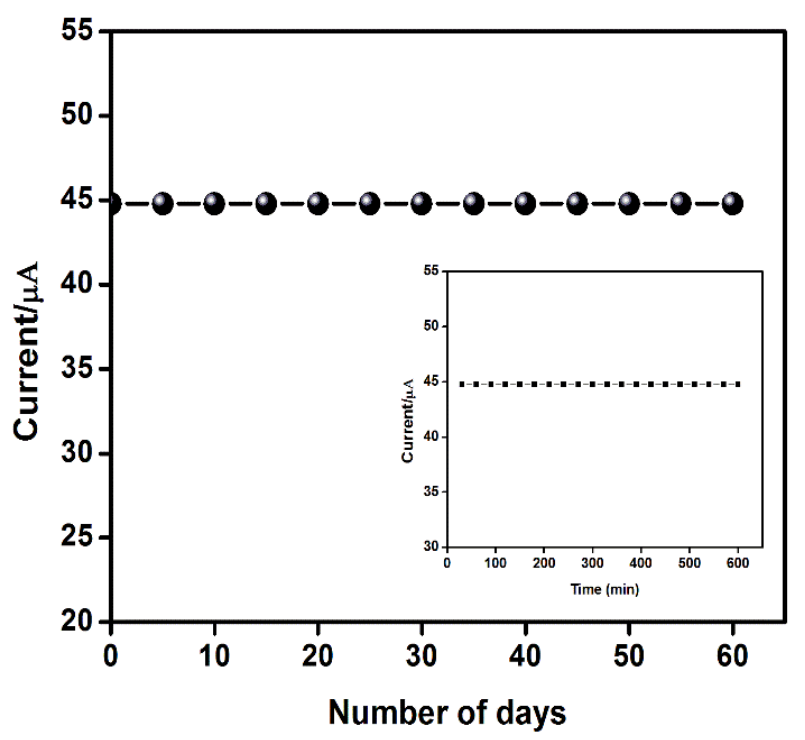

Figure 3. Long-term stability results of the Poly-TB modified screen-printed carbon sensor towards the oxidation current of tyramine $(82 \mu \mathrm{M})$. Calibration plot of current variation of tyramine vs. different time intervals (Inserts).

\section{Conclusions}

In this work, a Poly-TB modified screen-printed carbon electrode was successfully fabricated, characterized and first time used for tyramine detection. The developed sensor showed good stability, higher sensitivity, lower detection limits, inexpensive, repeatability and long-term durability. All these satisfactory results indicate that a poly (Toluidine blue) polymer film has excellent properties as a electroactive material for sensor surface modification. 
Author Contributions: Conceptualization, C.L., and M.B.; methodology, C.L.; software, C.L and M.B.; validation C.L, and M.B.; formal analysis, C.L.; investigation C.L.; resources, M.B.; data curation, C.L.; writing-original draft preparation, C.L.; writing-review and editing C.L.; M.B.; visualization, C.L.; supervision, M.B.; project administration, M.B.; funding acquisition, M.B. All authors have read and agreed to the published version of the manuscript.

Funding: This research was funded by the NOE Forschungs- und Bildungsges.m.b.H. (NFB) under the grant number LSC16-023.

Conflicts of Interest: The authors declare no conflict of interest.

\section{References}

1. Atta, N.F.; Abdel-Mageed, A.M. Smart electrochemical sensor for some neurotransmitters using imprinted sol-gel films. Talanta 2009, 80, 511-518.

2. McCabe-Sellers, B.J.; Staggs, C.G.; Bogle, M.L. Tyramine in foods and monoamine oxidase inhibitor drugs: A crossroad where medicine, nutrition, pharmacy, and food industry converge. J. Food Compos. Anal. 2006, 19, 58-65.

3. Galgano, F.; Favati, F.; Bonadio, M.; Lorusso, V.; Romano, P. Role of biogenic amines as index of freshness in beef meat packed with different bio-polymeric materials. Food Res. Int. 2009, 42, 1147-1152.

4. Yoon, I.; Seo, K.; Lee, S.; Lee, Y.; Kim, B. Conformational study of tyramine and its water clusters by laser spectroscopy. J. Phys. Chem. A 2007, 111, 1800-1807.

5. Coloretti, F.; Chiavari, C.; Armaforte, E.; Carri, S.; Castagnetti, G. Combined use of starter cultures and preservatives to control production of biogenic amines and improve sensorial profile in low-acid salami. J. Agric. Food Chem. 2008, 56, 11238-11244.

6. García-Villar, N.; Hernández-Cassou, S.; Saurina, J. Characterization of wines through the biogenic amine contents using chromatographic techniques and chemometric data analysis. J. Agric. Food Chem. 2007, 55, 7453-7461.

7. Mohan, C.O.; Ravishankar, C.N.; Srinivasa Gopal, T.K.; Ashok Kumar, K.; Lalitha, K.V. Biogenic amines formation in seer fish (Scomberomorus commers on) steaks packed with O2scavenger during chilled storage. Food Res. Int. 2009, 42, 411-416.

8. Erdogana, Z.O.; Akinb, I.; Kucukkolbasi, S. new non-enzymatic sensor based on TiO2-Ag/polypyrrole forelectrochemical detection of tyramine. Synth. Met. 2018, 246, 96-100.

9. López, M.S.P.; Redondo-Gómez, E.; López-Ruiz, B. Electrochemical enzyme biosensors based on calcium phosphate materials for tyramine detection in food samples. Talanta 2017, 175, 209-216.

10. European Food Safety Authority Panel on Biological Hazards, Scientific opinion on risk based control of biogenic amine formation in fermented foods. Efsa J. 2011, 9, 2393-2396.

11. Calbiani, F.; Careri, M.; Elviri, L.; Mangia, A.; Pistarà, L.; Zagnoni, I. Rapid assayfor analyzing biogenic amines in cheese: Matrix solid-phase dispersion followed by liquid chromatography-electrospray-tandem mass spectrometry. J. Agric. Food Chem. 2005, 53, 3779-3783.

12. Gianotti, V.; Chiuminatto, U.; Mazzucco, E.; Gosetti, F.; Bottaro, M.; Frascarolo, P.; Gennaro, M.C. A new hydrophilic interaction liquid chromatography tandemmass spectrometry method for the simultaneous determination of seven biogenicamines in cheese. J. Chromatogr. A 2008, 1185, 296-300.

13. Xu, Z.; Okada, J.; Timerbaev, A.R.; Hirokawa, T. Sensitive profiling of biogenicamines in urine using CE with transient isotachophoretic preconcentration. J. Sep. Sci. 2009, 32, 4143-4147.

14. Ladero, V.; Martinez, N.; Martin, M.; Fernandez, M.; Alvarez, M. qPCR for quantitative detection of tyramine-producing bacteria in dairy products, Food Res. Int. 2010, 43, 289-295.

15. Khana, M.Z.H.; Liua, X.; Zhua, J.; Ma, F.; Hua, W.; Liua, X. Electrochemical detection of tyramine with ITO/APTES/ErGO electrode andits application in real sample analysis. Biosens. Bioelectron. 2018, 108, 76-81.

16. Devi, C.L.; Narayanan, S.S. Poly(amido amine) dendrimer and silver nanoparticle-multi-walled carbon nanotubes composite with poly(neutral red)-modified electrode for the determination of ascorbic acid. Bull. Mater. Sci. 2019, 42, 73.

17. Lakshmi Devi, C.; Sriman Narayanan, S.; Sivaranjani, A. New electrochemical sensor for the detection of biological analytes using poly(amido amine) dendrimer and poly(Nile blue) modified electrode. $J$. Electroanal. Chem. 2019, 855, 113486. 
18. Devi, C.L.; Narayanan, S.S. Poly (amido amine) dendrimer/silver nanoparticles/multi-walled carbon nanotubes/poly (neutral red)-modified electrode for electrochemical determination of paracetamol. Ionics 2019, 25, 2323-2335.

19. Balasubramanian, S.; Tse-Wei, C.; Shen-Ming, C.; Karuppasamy, K.R.; Rajkumar, D.; Sea-Fue, W. Fabrication of Poly (Toluidine Blue O) Functionalized Multiwalled Carbon Nanotubes on Glassy Carbon Electrode for Hydrazine Detection. Int. J. Electrochem. Sci. 2018, 13, 4901-4910.

20. Madalina, M.B.; Emilia, G.M.; Brett, C.M.A. Electrochemical sensors and biosensors based on redox polymer/carbon nanotube modified electrodes: A review. Anal. Chim. Acta 2015, 881, 1-23.

Publisher's Note: MDPI stays neutral with regard to jurisdictional claims in published maps and institutional affiliations.

(C) 2020 by the authors. Submitted for possible open access publication under the terms and conditions of the Creative Commons Attribution (CC BY) license (http://creativecommons.org/licenses/by/4.0/). 